\title{
The Rural Wings Project: bridging the digital divide with satellite-provided Internet. Phase I: Identifying and analysing the learning needs of 31 communities in 10 countries
}

\author{
HENRIK HANSSON \\ Stockholm University, Sweden \\ PAUL MIHAILIDIS \\ University of Maryland, USA \\ KEN LARSSON \\ Stockholm University, Sweden \\ with \\ MENELAOS SOTIRIOU \\ International Projects Department Q-Plan S.A., Greece \\ SOFOKLIS SOTIRIOU \\ Research and Development Department, Ellinogermaniki Agogi, Greece \\ NIKOLAOS UZUNOGLU \& MICHAIL GARGALAKOS \\ Institute of Communications and Computer Systems, \\ National Technical University of Athens, Greece
}

\begin{abstract}
The digitally marginalised communities are in focus in the EU-funded Rural Wings project 2006-2008. The aim is to identify and analyse the user learning needs in non-connected communities and to meet these needs by providing satellite Internet broadband connections, education and tools. This article reports the findings of the user needs investigation of 31 communities in 10 countries in the initial phase of the project designed and coordinated by Stockholm University, Sweden. Each national coordinator conducted a user needs study in their country using a common framework of questions and guidelines. The sites were selected according to national and regional needs and where satellite-provided Internet is believed to be the long-term solution. The 31 communities selected can be summarised as (a) mainland/lowland communities, 10 (b) mainland/highland communities, 12 (c) island/lowland communities, 5, and (d) island/highland communities, 4 . The analysis reveals common threads of lack of infrastructure, accessibility and reliability concerning information and communication technology (ICT) implementation and containment in the community. There is a plethora of reasons for wanting more reliable and frequent Internet connections. Reasons range from educational opportunities, language opportunities, governmental inclusion, information/news outlets, and medical and weather initiative capabilities. This study provides in-depth macro-summaries of each participating country's user needs analysis in total. It also includes the actual analysis of each test site based on over 31 sites spanning 10 European nations. In addition, generalisations, comparisons and differences have been composed, to provide a framework for European trends in rural ICT access.
\end{abstract}

\section{Introduction}

The following study is an assessment of rural community needs concerning information and communication technology (ICT) access and satellite broadband Internet connection. The analysis 
includes scenarios from 31 rural community case studies from the following 10 participating nations: Cyprus, Estonia, France, Greece, Israel, Poland, Romania, Spain, Sweden, and the United Kingdom.

In addressing the following two general inquiries, this study should provide greater breadth and understanding into the complex issue of ICT implementation and educational learning structures in communities that have largely existed free of such advances and technologies. The general research questions are as follows:

1. What are the anticipated effects of implementing satellite broadband Internet access in rural communities?

2. How do the rural community members see themselves best utilising such access to information both educationally and socially?

It is important to note that the premise of user needs exists under the 'learning' umbrella. In the analysis that follows, user needs will be deconstructed based on numerous frameworks and categories. All of the categories implemented are in the form of learning and their premise is strictly educational.

\section{Background}

The premise of Rural Wings is to assess, implement, and oversee educational media technologies in communities that are presently unable to access reliable and up-to-date Internet and ICT technologies. The Rural Wings project is a multi-year initiative funded by the European Commission. The Rural Wings website promotes its goals as follows:

The Rural Wings project promotes a user-centered methodological approach, based on innovation practices and techniques. The ultimate goal is the transfer of knowledge and the adjustment of these practices in different knowledge spaces (learning@school, learning@work, learning@home) as a means for interaction between user needs and technological developments: the needs of users in rural areas feed the integration of the educational environment with dynamic requirements for new services or for the adaptation of existing ones. (Rural Wings, 2006)

Media access and saturation have exposed our society in such a way that 'knowledge' has become the fourth factor of economic production (Moore, 2001). Connections have been made between access to diverse information sources and greater civic participation, educational opportunity, and social capital (Putnam, 2000; Milner, 2002). Furthermore, notions of the digital divide and its complex positioning in the Western world are often the subject of greatest debate in those communities without proper digital dispositions.

In the twenty-first century, with the free flow of borderless information from all over the globe, all communities may stand to benefit from access to such information. However, certain communities in the European landscape still function without reliable access to the Internet and the proper infrastructure to utilise any connection they have. Much work has been conducted on the notion of distance education, ICTs, and the benefits they stand to provide to areas where demographics hinder access to the Internet, computers, and accessible information (Paul, 1990; Hansson \& van de Bunt-Kokhuis, 2004). Broadband Internet connection via satellite largely stands to lessen the current divide between the users and non-users.

Across Europe, projects have aimed to investigate ICT and technological initiatives that deal with convergence and demographics (Pavlovich \& McIntosh, 2004; Manovich, 2001). Rural Wings will build on such research to reveal the motivations of rural communities for having access to proper Internet and ICT infrastructures.

\section{Methods}

The research design is guided by principles presented by Creswell (2003), Patton (2004), Glaser (1998) and Strauss \& Corbin (1998). The study utilised multiple methods, both qualitative and quantitative. Both an empirical survey and in-depth interviews were conducted at each specifically chosen site. The methodology breaks down as follows: 
1. Survey. An empirical survey was created and distributed to all national coordinators (NC) for dissemination in their chosen sites. The survey was translated into different languages and fine tuned to suit specific cultural, political, and socio-economic dispositions.

2. Interviews. Each of the local coordinators conducted in-depth interviews on site with community leaders, members, and affiliates. The interview protocol was developed, and each interview was reported by national coordinators.

\section{Site Selection}

All of the case study sites are remote in some way or another. There exist both island and mainland communities in need of Internet connection. Terrestrial broadband connections are less likely to be an option because of the geographic disposition and a small and scattered habitat. The sites were categorised according to the following topographic characteristics and geographic location: (a) mainland/highland (mountain), 12 cases (b) mainland/lowland, 10 cases, (c) island/lowland, 5 cases (d) island/highland, 4 cases.

Information on four levels. The user needs analysis was conducted on four levels in each country:

1. Individual needs;

2. Community needs;

3. Regional needs;

4. National needs.

If needs could be assessed at all levels a site would be suitable for the Rural Wings project. National and regional policy also needs to be investigated in order to find out if a site was in need.

\section{Multimodal Data}

A rich description of a site includes not only interview information and statistics, but also images of (a) the landscape (topography), (b) activities (what do people do/work/study etc.?), (c) buildings (type and structures) and (d) maps (location? How to get there?)

\section{Data Collection, Analysis and Reporting}

Each national coordinator was responsible not only to collect relevant information in a national perspective, but also to process and analyse this information. Each country study is an independent part of the overall Rural Wings needs analysis survey.

\section{Limitations}

In light of this, no project exists without certain limitations. It is not our goal to provide an exact blueprint for all nations or all rural communities, but more a mural of the ways in which users will feel empowered, or stand to benefit, from broadband satellite Internet in their community. With that said, the following limitations should be acknowledged:

- Because each country's chosen sites greatly vary, the general findings will apply to each nation differently. At certain points, there is no grounding for similar results, and thus this report should be valuable in its explication, and not in its literal unpacking.

- As each project has a certain amount of resource allocation, a 'complete' sample of rural communities can never be taken. Thus, the decision over sites was left entirely up to the national coordinators (NC) and with these choices come obvious omissions. So as much as this project represents a general consensus, there are always other communities that could have changed the scope of the findings.

- Cultural, ethnic, and social differences inevitably influence national ideologies and national identities of each country. Thus, these intricacies should be accounted for when each country is including user needs into their implementation/scenario process. 


\section{Results}

Figure 1 shows the distribution of cases according to their location and topography. The geographical setting has both cultural and technical implications.

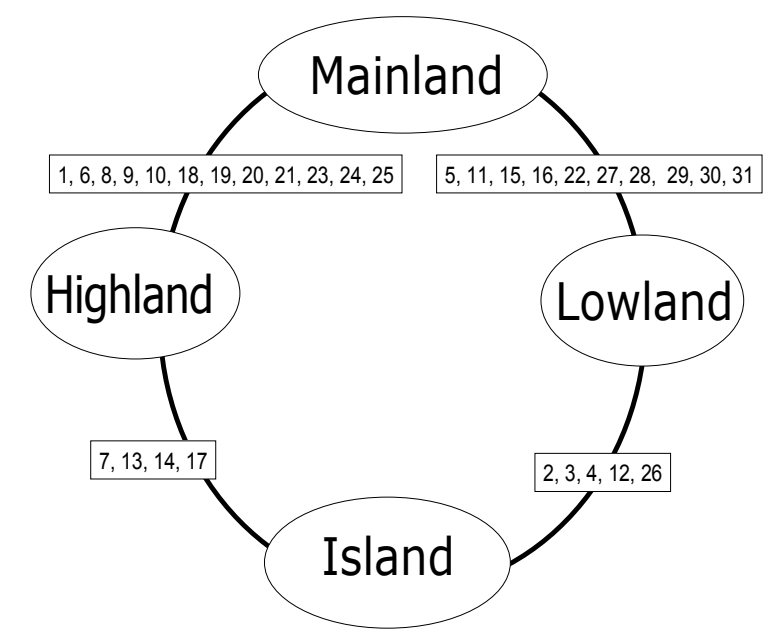

Figure 1. Topographic/geographic distribution of the selected sites (numbers refer to the sites listed in Table I).

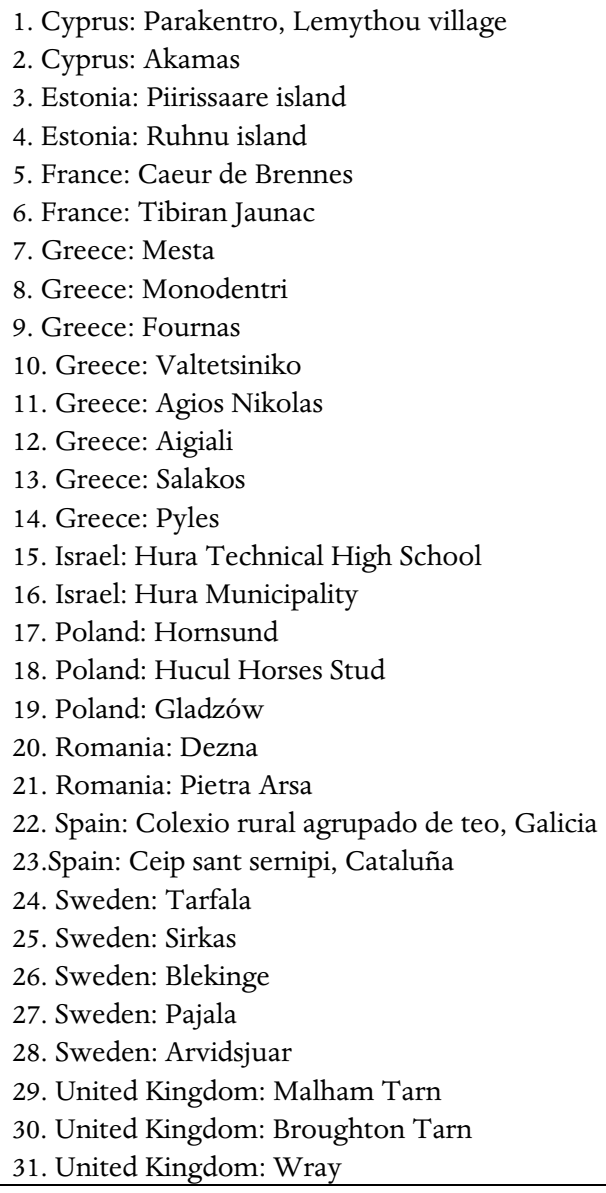

Table I. Sites selected for satellite broadband connections. 
Conceptual Framework: summary of user needs divided by countries

The user needs expressed in the case study reports showed differences and similarities between countries and sites. The less experienced users have a need for formal education and training in order to learn how to use the technology and improve their professional career skills. On the other hand, experienced users are mainly interested in attaining broadband Internet connection and using the technology for learning and professional development by mainly informal learning and communication with colleagues, professionals and friends. The involved countries therefore stressed different needs along the formal/informal learning dimension. Roughly, the countries focus was as follows:

1. Formal learning: Cyprus, Greece, Israel, Romania, Spain

2. Informal learning: Estonia, France, Poland, Sweden, United Kingdom

\begin{tabular}{|c|c|}
\hline Formal education & Informal learning \\
\hline Teacher training & $\begin{array}{l}\text { Communication and } \\
\text { learning via e-mail }\end{array}$ \\
\hline Training of farmers & $\begin{array}{l}\text { Communication and } \\
\text { learning via IP phone }\end{array}$ \\
\hline Training of doctors & $\begin{array}{l}\text { Communication and } \\
\text { learning via video }\end{array}$ \\
\hline $\begin{array}{l}\text { Information and } \\
\text { communication technology }\end{array}$ & $\begin{array}{l}\text { Search and find Internet } \\
\text { information }\end{array}$ \\
\hline Set selection of applications & $\begin{array}{l}\text { Open selection of } \\
\text { applications }\end{array}$ \\
\hline
\end{tabular}

Table II. Summary of user learning needs from cases.

Based on the user needs analyses, a conceptual model has been constructed that highlights the four basic categories of needs identified. These four categories penetrate all types of rural communities. The inner circle of the model identifies the types of rural communities selected by the national coordinators. The communities are divided as follows:

- Nature: farming-based communities in the mountains or extreme countryside;

- Educational research: research stations located in remote areas (i.e. Polar Circle, Arctic Circle, etc.);

- Schools: sites in which schools stand to benefit greatly from the connection (i.e. schools highlighted in user needs profiles);

- Entrepreneurship: rural communities built on tourism, on summer homes with remote yearround inhabitants, or places utilised entirely for leisure activities;

- Municipality: a township in which community services stand to be most affected by Rural Wings (i.e. as highlighted in user needs profiles).

Categorically, these designations represent the spectrum of rural communities located through the user needs analyses. These designations are static and stand to overlap, connect, and are subject to continuous evolution and change. Further, a brief explanation of the four categories of user needs will precede the model:

(a) Education: involves the educational possibilities based on having ICT infrastructure combined with reliable broadband Internet access via satellite. E-learning, educational information and informal learning were highlighted in the reports.

(b) Communication: users all reported the ability to feel more 'connected' to the world through having access to global, borderless information. They also alluded to the idea of becoming more tolerant of global issues with the attainment of wider and more diverse perspectives.

(c) Involvement: all communities mentioned becoming more active in community/national issues and have better services for government users. 
(d) Business: users in tourist/leisure areas spoke of the ability to advertise and promote their location, begin expanding business ideas through the Internet and expand business/tourism knowledge through the Internet.

\section{USER TRENDS - 4 CATEGORIES OF COMMUNITY NEEDS}

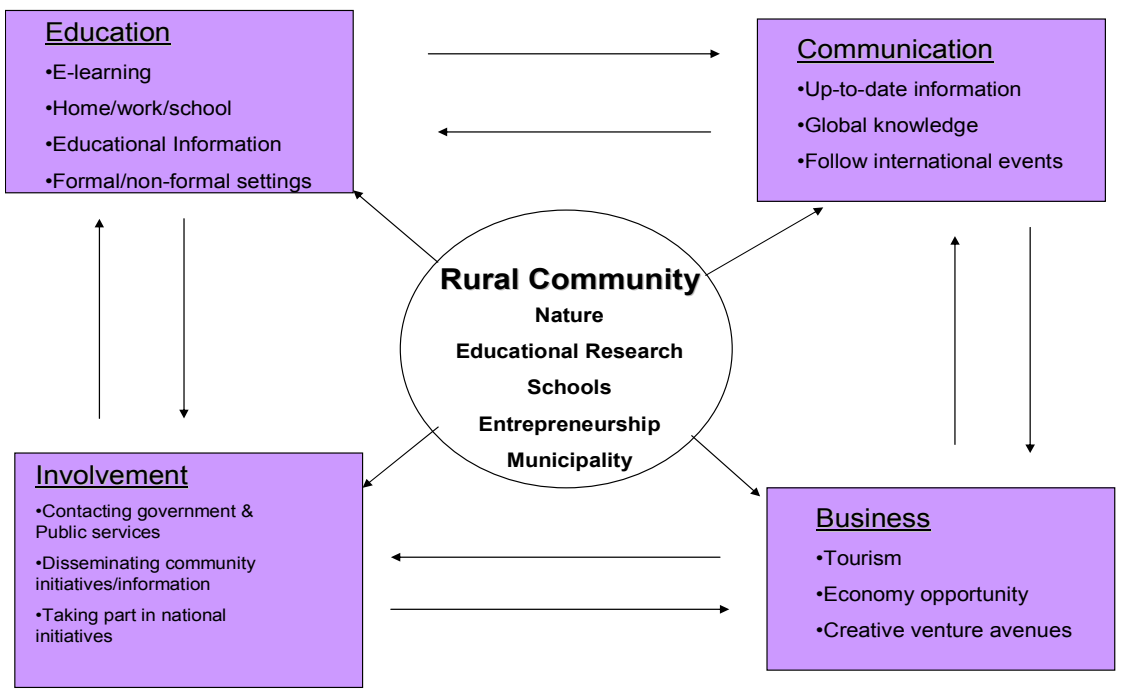

Figure 2. User trends - four categories of community needs.

Based on the individual user profiles, the communities as a whole, across borders and community types, stand to gain much. This impact stands to lessen notions of the digital divide. However explanatory Figure 3 seems, it is relevant to point out, based on the information of the individual user and the community as a whole, the promise that implementing such ICT and Internet access stands to provide to rural communities.

\section{Broadband Satellite Wireless Internet}

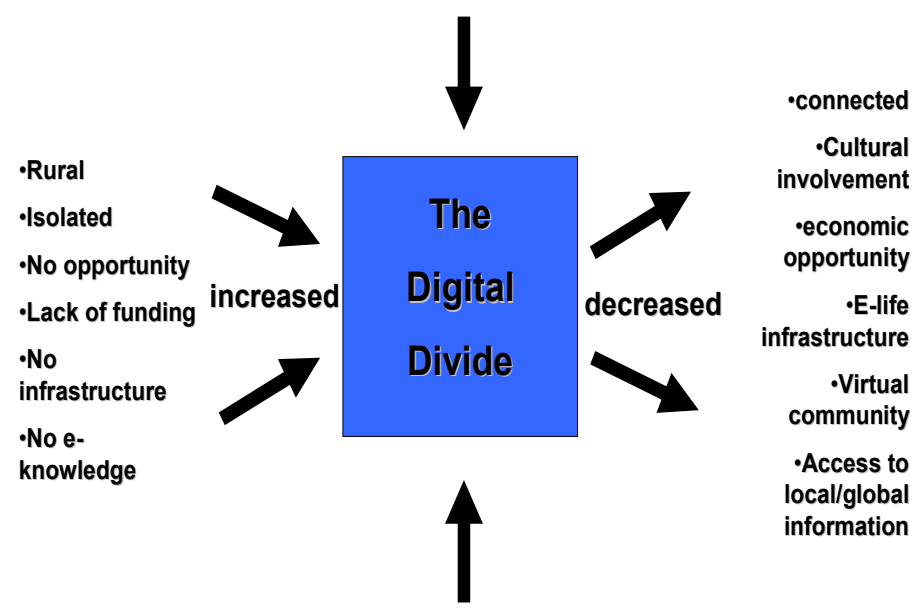

ICT Infrastructure

Figure 3. ICT effects on the digital divide in rural communities. 


\section{Discussion}

In general, the task of assessing the user needs was both inclusive and elaborative at the same time. While most communities spoke positively of the educational opportunities of ICT infrastructure in their society, they did so for a variety of reasons. Nonetheless, there exists a fundamental belief that all communities shared, which is that ICT infrastructure and broadband satellite connection to the Internet stands to improve educational and lifestyle dispositions in rural communities. There were very few instances of reports that people were wary of such an initiative impacting their community in a negative light. Most of the indifferent participants were of older generations, and the reports did not note negativity, but rather sheer indifference or reluctance to change.

Thus, what the user needs profiles tell us is that the possible allocation of solid Internet connections in rural communities, across Europe, has been received, in general, positively. Specific discussions concerning the digital divide, e-learning, and communication will help to situate the results in the context of the larger theoretical dispositions they apply to. The following analyses should help to see the aggregate generalisations reached from the specific data:

(a) The digital divide. The digital divide has long been a highly contested and volatile topic (Norris, 2001). While few would debate its existence, many would debate the extent, the major implications, and, the 'real' affect of the theory. Furthermore, the digital divide is vastly different depending on which community, country, or part of the world one is in. This analysis reinforced through the user profiles - that the digital divide, in any capacity previously studied, would be decreased. All rural communities reported numerous benefits possible through faster, more secure and stable Internet access. All aspects of the digital divide - education, economy, involvement, and so on - were addressed by the users. There was a general and overwhelming consensus as to how the community would benefit greatly from such an initiative.

(b) E-learning/e-administration. While e-learning and e-administration are broad terms that can encompass many different attributes and signifiers, they were both broadly touched upon throughout the analyses. They are included in the same write-up because depending on whether a school or municipality was the site chosen, or the participant(s) interviewed, these terms were generally alluded to. For example, school sites would all mention the ability to have greater information available, conduct work from home or outside of the school, and have increased contact with the school community. The use of ICTs, and particularly the Internet, as a tool to achieve better 'government' - the definition of e-government given by the Organisation for Economic Cooperation and Development - is a major concern for all developed countries. A pledge of better services for government users and greater efficiency at a considerably reduced cost, e-government is as much an opportunity as a necessity. E-administration was spoken of both in terms of the municipality disseminating information to its community members more easily and in a timelier way, and of the ability for community members to be more involved in local/national affairs. Thus, overall, both of these terms, in their broadest sense, were highly touted in the possible user benefits of ICT infrastructure and broadband Internet access.

(c) 'Rural'. The term 'rural' alluded to different demographics for different countries. For example, while Estonia and Israel chose what most would consider traditional rural communities mountain and desert towns - Poland chose as one of its sites a research base in the Polar Circle. Further, Sweden also chose a research station on a mountain side, and the United Kingdom picked a 'rural business park' as one of its participating sites. Thus, the definition of rural was challenged in each country but the findings were similar across all demographics. Most spoke primarily about the educational opportunities, the economic opportunities, and the participatory opportunities (government involvement). Most communities primarily alluded to these aspects no matter what the term 'rural' denoted.

(d) 'Life' conditions. The life conditions of a community largely depended on the country and type of rural community (desert, mountain, research, etc.) For example, numerous 'research bases' in rural areas were used, and thus the technological infrastructure was quite strong. The life conditions of the rural communities largely dictated the user needs. However, as there was a large and diverse sample of countries involved in the user needs analysis, the needs, over the range and scope of countries, turned out to be quite similar.

(e) Community. The term 'community', in the case of the selected sites, has been stretched to its furthest limits. The national coordinators have chosen sites from those with populations of 10 
people, to business parks and research bases in the North Pole. Thus, the idea of community is both an advantage and limitation in this context. The introduction of ICTs and reliable broadband Internet access stands to change notions of community in each rural site. This is an intangible result of the implementation process in terms of sustainability of the community with new technology. It is also a longitudinal effect on community, which it was not possible to measure during the duration of the study. However, notions of physical community and virtual community should be discussed during the implementation phase and throughout the project, as the effects on traditional community affairs could dramatically alter the dynamic of the specific site.

(f) Culture and economy. This point has much to do with 'life conditions' but can be separated by the idea that all cultures are unique and shared at the same time. Thus, culture becomes an interesting precursor of the way that users view ICTs and the Internet and, further, the benefits they will have once broadband access is implemented. Moreover, as the countries all have different economies, performing at different levels, it is important to note that the infrastructure available to each nation depends on its economic health. However, these two points were overshadowed by the striking similarities in the user needs analyses.

The analyses were conducted not only to address the specific and practical needs of the rural communities, but to address major theoretical issues surrounding the implementation of ICTs into rural communities. Curricula/standards cannot be successfully implemented into any community without understanding what the community will think of these implementations, and how the community will utilise them. Thus, the aim of this study is to provide the ideas and opinions of the end users. This should inevitably make the planning, implementation and end result of the actual platforms and tools more useful, practical and enlightening.

\section{Conclusion}

The community needs expressed in the case study reports show numerous similarities and differences between countries and sites. The less experienced users have a more pressing need for formal education and training in order to learn how to use the technology and improve their professional skills. Alternatively, experienced users are mainly interested in attaining infrastructure and stable connections to strengthen learning capabilities and professional development by utilising informal learning and communication with colleagues, professionals and friends. The involved countries therefore stressed different needs along the formal-informal learning dimension. The specific formal and informal user needs that were extracted from the case study sites are as follows:

- Formal learning: teacher training, training of farmers, training of doctors, training to use ICT, and

- Informal learning: communication and learning via email, communication and learning via IP phone, communication and learning via video, independent Internet use.

Whether formal or informal, this study, as part of a larger multi-year European Community project, stands to provide great insight and explication for what educational benefits stand to be gained from providing proper technological structures and educational reinforcements in rural communities around Europe and beyond.

\section{Note}

[1] See http:/ / www.itandsociety.org for thorough digital divide debate and analysis.

\section{References}

Creswell, John (2003) Research Design: qualitative, quantitative, and mixed methods approaches, 2nd edn. Thousand Oaks: Sage.

Glaser, Barney G. (1998) Doing Grounded Theory: issues and discussions. Mill Valley: Sociology Press.

Hansson, H. \& van de Bunt-Kokhuis, S. (2004) E-learning and Language Change - observations, tendencies and reflections, First Monday. http:/ / www.firstmonday.org/issues/issue9_8/hansson/index.html (accessed 18 September 2006).

Manovich, Lev (2001) The Language of New Media. Cambridge, MA and London: MIT Press. 
The Rural Wings Project

Milner, H. (2002) Civic Literacy: how informed citizens make democracy work. Dartmouth, NH: University Press of New England.

Moore, M.G. (2001) Distance Education in the United States: the state of the art. From a series of lectures of educational use of ICT and virtual education. http: / www.uoc.edu/web/eng/art/uoc/moore.html (accessed 18 September 2006).

Norris, Pippa (2001) Digital Divide: civic engagement, information poverty, and the Internet worldwide. Cambridge: Cambridge University Press.

Patton, Michael Quinn (2004) Qualitative Research and Evaluation Methods, 4th edn. London: Sage.

Paul, R.H. (1990) Open Learning and Open Management: leadership and integrity in distance education. London: Kogan Page.

Pavlovich, John V. \& McIntosh, Shawn (2004) Converging Media: an introduction to mass communication. Boston: Allyn \& Bacon.

Putnam, R. (2000) Bowling Alone: the collapse and revival of American community. New York: Simon \& Schuster.

Rural Wings Website. Goals and Aims. http: / / www.ruralwings-project.net/RW/Project/Description.aspx (accessed 18 September 2006).

Strauss, Anselm L. \& Corbin, Juliet (1998) Basics of Qualitative Research: techniques and procedures for developing grounded theory, 2nd edn. Thousand Oaks: Sage.

HENRIK HANSSON is senior lecturer in the Department of Education, Stockholm University, Sweden. He has conducted numerous international projects and studies related to distance, open and flexible education, Internet communication and cultural differences. Correspondence: Henrik Hansson, Institute of International Education, Department of Education, Stockholm University, SE-106 91 Stockholm, Sweden (henrik.hansson@interped.su.se).

PAUL MIHAILIDIS is Director of Media Literacy Initiatives at the International Center for Media and the Public Agenda at the University of Maryland, College Park, USA, where he is also visiting faculty in the Philip Merrill College of Journalism. He also consults for numerous European Commission-initiated projects on education and media technology. Correspondence: Paul Mihailidis, Philip Merrill College of Journalism, 1117 Journalism Building, University of Maryland, College Park, MD 20742, USA (pmihailidis@jmail.umd.edu).

KEN LARSSON is lecturer in User Centred Iterative Design at the Department of Computer and Systems Sciences at Stockholm University, Sweden. He has been involved in several studies and projects on e-learning and design of e-learning. 